\title{
Integração comercial entre Brasil e Argentina na cadeia produtiva tritícola
}

\author{
Sinara Pizzi Martins ${ }^{1}$ \\ Marlussi de Oliveira Garzão \\ Nilson Luiz Costa ${ }^{3}$ \\ Simone Bueno Camara ${ }^{4}$
}

\begin{abstract}
Resumo
O agronegócio brasileiro vem se destacando pela sua importância econômica e produtiva, principalmente pelas suas cadeias produtivas, como da soja e de carnes. Esse potencial coloca o país com um grande produtor de alimentos frente a outros países mundialmente. Entretanto, ao mesmo tempo em que algumas cadeias produtivas se destacam, outras são extremamente dependentes de importações para suprir a demanda interna, é o caso da cadeia produtiva do trigo, que importa grandes quantidades de cereais, sobretudo da Argentina. Nesse sentido, o presente estudo tem a finalidade de compreender a integração comercial entre o Brasil e a Argentina no setor tritícola, identificando as principais razões que fazem o Brasil ser tão dependente das importações deste cereal do país vizinho. A metodologia utilizada neste caso consiste de uma pesquisa bibliográfica e de um estudo de caso, com coleta de dados secundários e estatísticos coletados em sites da United States Department of Agriculture (USDA), Ministério da Indústria, Comércio Exterior e Serviços (MDIC), Companhia Nacional de Abastecimento (CONAB) e Associação Brasileira das Indústrias do Trigo (ABITRIGO). Especificamente, os principais resultados evidenciados são que o Brasil não apresenta condições favoráveis de clima e solo para a produção deste cereal de boa qualidade e em quantidade suficiente, além de serem insuficientes os incentivos à produção desse cereal no país. $\mathrm{O}$ trigo argentino, portanto, apresenta boa qualidade, uma vasta cadeia de incentivos governamentais para a produção, bem como, tarifas alfandegárias menores, tudo isso o torna mais barato quando comparado ao trigo produzido em solo brasileiro.
\end{abstract}

Palavras-chave: Agronegócio. Integração Comercial. Trigo. MERCOSUL.

\section{Commercial integration between Brazil and Argentina in the wheat production chain}

\begin{abstract}
Brazilian agribusiness has been notable for its economic and productive importance, mainly for its productive chains, such as soy and meat. This potential puts the country with a major food producer in front of other countries worldwide. However, at the same time as some productive chains stand out, others are extremely dependent on imports to supply domestic demand, as is the case of the wheat production chain, which imports large quantities of grain, especially from Argentina. In this sense, the present study aims to understand the commercial integration between Brazil and Argentina in the wheat sector, identifying the main reasons that make Brazil so dependent on imports of this cereal from the neighboring country. The methodology used in this case consists of a bibliographical research and a case study, with collection of secondary and statistical data collected on websites of the United States Department of Agriculture (USDA), Ministry of Industry, Foreign Trade and Services (MDIC), National Supply Company (CONAB) and the Brazilian Association of Wheat Industries (ABITRIGO). Specifically, the main results evidenced are that Brazil does not present favorable conditions of climate and soil for the production of this cereal of good quality and in sufficient quantity, besides the insufficient incentives to the production of this cereal in the
\end{abstract}

1 Mestranda no Programa de Pós-Graduação em Agronegócios (PPGAGR/UFSM) da Universidade Federal de Santa Maria-UFSM, Campus Palmeira das Missões. https://orcid.org/0000-0002-6728-5667

2 Mestranda no Programa de Pós-Graduação em Agronegócios (PPGAGR/UFSM) da Universidade Federal de Santa Maria-UFSM, Campus Palmeira das Missões. https://orcid.org/0000-0002-2187-4546

3 Doutor em Ciências Agrárias (UFRA). Professor do Programa de Pós-Graduação em Agronegócios da Universidade Federal de Santa Maria (UFSM), Campus de Palmeira das Missões. http://orcid.org/0000-0003-2000-1521

4 Mestranda no Programa de Pós-Graduação em Agronegócios (PPGAGR/UFSM) da Universidade Federal de Santa Maria-UFSM, Campus Palmeira das Missões. https://orcid.org/0000-0002-5303-1578 
country. Argentine wheat, therefore, shows good quality, a vast chain of government incentives for production, as well as lower customs tariffs, all of which makes it cheaper when compared to wheat produced on Brazilian soil.

Keywords: Agribusiness. Business Integration. Wheat. MERCOSUL.

\section{Introdução}

O agronegócio brasileiro vem se destacando ao longo dos anos pela sua relevância econômica e produtiva, contribuindo positivamente na balança comercial do país. Nesta perspectiva, algumas cadeias produtivas ganham destaque, principalmente, a cadeia produtiva da soja, de carnes, de café e de suco de laranja. Entretanto, o país é muito dependente das importações de trigo (Triticum) dado o consumo superior à produção interna. Este é um dos principais cereais utilizado na produção de alimentos, tanto humano quanto animal (JESUS JÚNIOR; SIDONIO; MORAES, 2011).

Segundo dados da United States Department of Agriculture (USDA) na safra de 2018 o Brasil ocupou a terceira posição entre os países que mais importaram trigo a nível mundial, foram 7,5 milhões de toneladas, atrás apenas do Egito que importou 12,5 milhões e da Indonésia com 10 milhões de toneladas. Além disso, cabe salientar que a maior parte das importações de trigo do Brasil provém da Argentina $\left(87,18 \%\right.$ do total $\left.{ }^{1}\right)$, país que vem se tornando competitivo na produção deste cereal e constituindo-se atualmente o maior país exportador do Mercado Comum do Sul (MERCOSUL) (MDIC, 2018; ABITRIGO, 2018).

Desta forma, torna-se interessante compreender a forma como se estabelece a integração comercial entre esses dois países (Brasil e Argentina) com relação à cadeia tritícola, respondendo a seguinte problemática: quais são as principais razões que levam o Brasil a aceitar a condição de importador de trigo (principalmente da Argentina) ao invés de fomentar internamente o aumento de sua produção, dada sua importância como matéria-prima base para a produção de alimentos?

Nesse sentido, o objetivo geral deste trabalho é compreender a integração comercial entre o Brasil e a Argentina no setor tritícola, no contexto do Mercosul, e identificar as principais razões de o Brasil ser tão dependente das importações deste cereal da Argentina, por meio do desenvolvimento de três objetivos específicos: identificar a partir da literatura existente, os principais incentivos técnicos e econômicos na produção de trigo criados ao longo do processo histórico destes países; descrever o atual cenário da cadeia tritícola no Brasil e na

\footnotetext{
${ }^{1}$ Dado referente ao ano safra de 2018 (ABITRIGO, 2018).
} 
Argentina; destacar alguns pontos remotos em comparação a outros países e apresentar novas iniciativas que vem sendo alavancadas nesse setor.

Este trabalho contribui com as discussões sobre o assunto, na medida em que procura estudar as cadeias produtivas do agronegócio brasileiro, em caso especial a cadeia produtiva do trigo, de forma a compreender suas particularidades e identificar seus pontos limitantes. Além disso, procura contribuir para a criação de medidas e políticas voltadas a setores menos desenvolvidos dentro do agronegócio brasileiro, de modo a agregar mais valor e potencial competitivo a este, bem como, promover o desenvolvimento socioeconômico.

O presente artigo está dividido em quatro seções, além desta introdução. A segunda é composta pela descrição dos materiais e métodos utilizados na pesquisa; a terceira pelos resultados encontrados, com ênfase na análise do contexto histórico da cadeia produtiva do trigo no Brasil e na Argentina, bem como os incentivos e as limitações ao cultivo deste cereal, além de buscar caracterizar o cenário mercadológico. Por fim, a quarta seção apresenta as considerações finais deste tema.

\section{Materiais e métodos}

A pesquisa desenvolvida por este trabalho possui natureza básica, cujo objetivo é "gerar conhecimentos novos úteis para o avanço da ciência sem aplicação prática prevista" (PRODANOV; FREITAS, 2013, p. 51). Quanto à forma de abordagem do problema de pesquisa, este estudo se caracteriza por uma pesquisa qualitativa, muito utilizada no campo das ciências sociais, ao qual procura compreender e explicar o contexto e a dinâmica das relações sociais do objeto em estudo (RAMOS, 2009; GERHARDT; SILVEIRA, 2009).

Em relação aos objetivos do trabalho também se classifica como uma pesquisa exploratória, cuja finalidade é "proporcionar maior familiaridade com o problema com vistas à torná-lo mais explícito" (RAMOS, 2009, p. 183). Segundo os autores, a pesquisa exploratória é realizada por levantamentos bibliográficos, entrevistas, entre outros, e "geralmente assume a forma de pesquisa bibliográfica e estudo de caso" (RAMOS, 2009, p. 183).

Desta forma, o procedimento de coleta de dados e o método de pesquisa envolvem justamente estes dois processos: levantamento bibliográfico de informações e um estudo de caso. Para o levantamento bibliográfico foram utilizados artigos científicos, livros, relatórios e dados estatísticos secundários. Os dados estatísticos foram coletados nos sites do Departamento de Agricultura dos Estados Unidos (USDA), do Ministério da Indústria, Comércio 
Exterior e Serviços (MDIC), da Companhia Nacional de Abastecimento (CONAB) e da Associação Brasileira das Indústrias do Trigo (ABITRIGO). Estes dados correspondem aos últimos cinco anos (2014 a 2018), período em que se percebe elevação nos volumes importados de trigo pelo Brasil da Argentina.

Já o estudo de caso é caracterizado por coletar e analisar informações de determinado (os) indivíduo (os) com finalidade de estudar seus aspectos peculiares de forma aprofundada (PRODANOV; FREITAS, 2013). No caso deste trabalho o estudo de caso é utilizado no estudo em particular das relações comerciais da cadeia produtiva tritícola entre o Brasil e a Argentina, no contexto do Mercosul. Procura-se, assim, compreender as relações, limitações e potencialidades do trigo entre esses dois países.

\section{Resultados e discussões}

\subsection{MERCOSUL e a integração comercial Brasil e Argentina}

O processo de abertura comercial internacional proporcionou muitos ganhos aos países, principalmente quanto a maior ampliação da oferta de bens e serviços, resultando em escalas produtivas (KRUGMAN; OBSTFELD, 1999). Nessa perspectiva, segundo as contribuições de Adam Smith (1776) em sua teoria das "vantagens absolutas", a partir dessas trocas comerciais, cada país acaba se especializando naquilo que faz de forma mais eficiente e troca (exporta) esses bens por bens (importa) da qual é pouco eficiente (em termos de altos custos de produção e produtividade). Assim, ambos os países que efetuam essas trocas se beneficiam (KRUGMAN; OBSTFELD, 1999).

Contudo, mesmo que esses países não dispunham de nenhuma vantagem absoluta, estes ainda podem ter ganhos no comércio internacional. Segundo Gontijo (2007) esses ganhos estão associados às vantagens comparativas, associada às distintas produtividades de cada país, ou seja, os países devem se especializar em bens da qual possuam menor custo de oportunidade ou maior produtividade de trabalho (GONTIJO, 2007; FIGUEIREDO; SANTOS, 2005).

Nessa perspectiva de ganhos de comércio e com o fim da Segunda Guerra Mundial, a integração comercial entre países teve um papel fundamental na recuperação de economias devastadas, sobretudo, anos mais tarde nos processos de globalização comercial mundial, em 1980 (DATHEIN, 2005). No caso da América Latina, a integração econômica entre seus países 
ocorreu a partir de 1960, com a formação da Associação Latino-Americana de Livre Comércio (ALALC), influenciada pelo Tratado de Montevideo e que mais tarde, em 1980 foi substituída pela Associação Latino-Americana de Desenvolvimento e Integração (ALADI) (DATHEIN, 2005).

Desta forma, as interações comerciais entre o Brasil e Argentina tornaram-se mais próximas com a abertura e interação de seus mercados e economias. O passo inicial desta integração deu-se com a assinatura, em 1985, da Declaração do Iguaçu e com o Programa de Integração e Cooperação Econômica (PICE), de 1988, "removendo totalmente os impostos de importação e as restrições não tarifárias ao comércio de bens e serviços" entre esses dois países (DATHEIN, 2005, p. 27; MAEHLER et al., 2016).

Essas interações motivaram a assinatura de um terceiro documento, o Tratado de Assunção em 1991, cujo objetivo principal foi a criação de um Mercado Comum do Sul, denominado MERCOSUL, integrando a Argentina, Brasil, Paraguai e Uruguai. Com essa integração comercial houve a redução de tarifas aos países membros e livre comércio de bens e serviços, eliminação de barreiras alfandegárias, bem como, a criação da Tarifa Externa Comum (TEC) com países que não faziam parte do acordo (DATHEIN, 2005; GRANATO; BATISTA, 2018).

Portanto, segundo Maehler et al. (2016, p. 796), com a criação do MERCOSUL houve "crescimento do comércio e da especialização, no qual o Brasil aumentou o seu grau de industrialização, enquanto que os demais países expandiram e modernizaram seus respectivos setores agrícolas". Além disso, as maiores integrações dentro desse bloco econômico são transacionadas pelo Brasil e a Argentina, sendo estes principais parceiros no que consiste o comércio bilateral (MAEHLER, 2016).

Conforme Fávero (2017), o intercâmbio comercial entre o Brasil e a Argentina no ano de 2016 atingiu US\$ 22 milhões de dólares, sendo que entre os produtos mais comercializados entre esses países está o intercâmbio do trigo. $\mathrm{O}$ autor reforça que entre os principais pontos fortes da importação de trigo argentino estão à qualidade do cereal e menor tarifa alfandegária. Além disso, o Brasil não é autossuficiente na produção de trigo decorrente da oferta ser menor que a demanda interna, apresentar baixa qualidade, assim como riscos quanto às condições climáticas e de solo (FÁVERO, 2017).

\subsection{Contexto histórico do cultivo de trigo no Brasil e as políticas de fomento ao setor}

O trigo é pertencente à família das gramíneas, também conhecido pelo gênero triticum, é o segundo cereal mais produzido e consumido no mundo, considerado um importante 
insumo básico na dieta alimentar humana e animal (OLIVEIRA NETO; CANDICE, 2017). Este cereal representou na safra de 2017/2018 participação percentual de 26,3\% dos principais grãos produzidos mundialmente, ficando atrás somente do milho que teve representatividade de 36,3\% nesta mesma safra (USDA, 2018). Entretanto, é pouco produzido no Brasil, representou na safra de 2017/2018 apenas 1,8\% da produção nacional de grãos, atrás da produção da soja $(49,1 \%)$, de milho $(42,5 \%)$ e de arroz $(5,3 \%)$, respectivamente (CONAB, 2018).

Soares (1980) esclarece que, o primeiro cultivo de trigo no Brasil deu-se a partir dos anos de 1534, sendo que as primeiras sementes chegaram à Capitania de São Vicente (Litoral de São Paulo). Contudo, o cultivo de trigo no país somente adquiriu importância econômica em 1737, difundida no Rio Grande do Sul pelos colonos vindos dos Açores. O Brasil até 1811 era exportador de trigo, contudo, esta primeira fase da triticultura brasileira foi abruptamente interrompida pela ferrugem, doença que foi fulminante para o grão (SOARES, 1980).

A segunda fase da triticultura no Brasil ocorreu a partir de 1950, caracterizada e incentivada pela modernização agrícola (BRUM et al., 2003), seguida da criação do Departamento de Trigo, subjugado à Superintendência Nacional de Abastecimento (SUNAB). Esta foi uma forma de intervenção do Governo Brasileiro na maneira como se estabelecia a comercialização do trigo e da farinha, através da consolidação do Decreto de Lei n²10/1967 (BRASIL, 1967; CUNHA, 2009).

A consolidação deste decreto de lei tinha a finalidade de regulamentar a comercialização estatizada e proibir o comércio do trigo nacional ou importado pelo setor privado, pendurando até o final de 1990, com a ideia de alcançar a autossuficiência novamente nesse setor (BRASIL, 1967; CUNHA, 2009). Em 1973 foi criada a Empresa Brasileira de Pesquisa Agropecuária (EMBRAPA) que reforçou os estudos de todos os aspectos da cultura como clima, genética e produtividade (GARCIA, 2011).

A intervenção estatal teve grande importância no período de 1970 a 1989, ao qual foram criadas políticas de preços mínimos, de distribuição de cotas aos moinhos e de compra de toda a produção. Estas mudanças se deram através de uma nova Lei no 8.096/1990, passando de uma conjuntura de políticas próprias de suporte à comercialização para a integração à Política de Garantia de Preços Mínimos (PGPM) (BRASIL, 1990; CUNHA, 2009). O objetivo era reduzir custos e dar uma maior flexibilidade à PGPM diante da concorrência nacional, passo que após, em 1997, surge o Prêmio de Escoamento da Produção (PEP) (BRASIL, 1990; CUNHA, 2009). 
Entretanto, os moinhos passaram a receber trigo importado, sobretudo, por "preços relativamente mais baixos dos grãos em comparação ao nacional, melhor qualidade e maiores facilidades de financiamento" (BRUM; MULLER, 2008, p. 150). Desta forma, como medida protetiva, "a reforma da política extinguiu os preços de aquisição e introduziu o trigo na pauta de preços mínimos" (BRUM; MULLER, 2008, p. 150). As primeiras safras subsequentes à desestatização foram destinadas ao governo ou foram comercializadas aos moinhos a preços muito mais baixos do que praticados anteriormente (BRUM; MULLER, 2008).

Com os preços de venda mais baixos a produção nacional foi gravemente afetada e essa falta de incentivos, principalmente de rendimentos ao produtor, gerou consequências, como sucessivas quedas de áreas cultivadas e de produção do grão (BRUM; MULLER, 2008). O governo não foi capaz de deter a substancial redução da produção nacional, apesar da adoção de novos mecanismos de incentivo, além da manutenção de políticas de apoio e mecanismos tradicionais (BRUM; MULLER, 2008). Para Perosa e Paulillo (2009) a partir do lançamento do MERCOSUL (1991) e particularmente a partir da consolidação da zona de livre-comércio (1995), a importação de trigo feita pelo Brasil do Canadá, da Argentina e dos Estados Unidos ganhou força, desestimulando ainda mais a produção interna. Os moinhos de trigo brasileiros passaram então a receber em grandes quantidades o grão importado, classificado e separado. Contexto em que fixa a Argentina como maior exportadora de trigo para o Brasil (PEROSA; PAULILLO, 2009).

Entretanto, entre as mudanças do setor do trigo, o Brasil teve ainda de se adequar a algumas normativas, uma delas criada no ano de 1995 pelo o Ministério da Agricultura Pecuária e Abastecimento (MAPA), a portaria $n^{\circ} 167$, de 29 de julho, que diz respeito à classificação brasileira oficial de consideração da qualidade da farinha (ABITRIGO, 2011). Em 1999 esta portaria foi substituída pela Instrução Normativa (IN) do MAPA, IN n 01/1999 - Norma de Identidade e Qualidade do Trigo - com objetivo a comercialização interna do grão, que seguia a classificação física por tipo 01, 02 e 03, diferenciando-se então as classes em função da força geral do glúten e do número de queda, sendo o grão classificado em brando, pão, melhorador, Durum e outros usos (BRASIL, 1999; CUNHA, 2009). Esse sistema de classificação perdurou até o ano de 2007 (PEROSA, 2007).

Atualmente, a classificação comercial de trigo brasileira é regulamentada pela IN Mapa $n^{\circ} 38 / 2010$, direcionada para adequação dos padrões oficiais de qualidade exigidos pelo mercado nacional (PEROSA, 2007). Neste contexto, Corte et al. (2015) abordam que o consumo e a produção de trigo brasileiros passaram por um período de regulamentação estatal que 
resultou quase em autossuficiência, mas que acabou revertendo-se para um cenário totalmente contrário, de desestímulo ao setor interno, redução de área plantada, dependência de importações e baixa competitividade da produção tritícola brasileira.

Entre os fatores que construíram para este cenário estão à queda nos subsídios e impostos de importação, os quais abriram entrada para o trigo e seus derivados de outros países (CORTE et al., 2015). Nesta perspectiva, o produtor de trigo brasileiro além de não possuir, em sua maioria, condições e incentivos que o permitam estruturar-se na cadeia produtiva, de modo que seu grão possa competir com o produto externo, enfrenta uma situação antiga, a total falta de perspectiva para a comercialização dos estoques das safras, tanto daquelas passadas quanto dos presentes, acumulando grãos nos armazéns (CORTE et al., 2015).

\subsection{Cultivo de trigo na Argentina}

O cultivo de trigo na Argentina causou grandes transformações na agricultura do país, sobretudo, no desenvolvimento da agricultura extensiva. Segundo a Secretaria de Agricultura, Pecuária, Pesca e Alimentos da Argentina (SAGPYA, 2003) o processo de integração e desenvolvimento do cultivo de trigo no país teve como principal influência a vinda de mão-deobra imigrante europeia, ao qual influenciaram a estrutura social, cultural e econômica do país (SAGPYA, 2003). O cultivo do trigo na Argentina teve início no ano de 1527, onde seu primeiro cultivo deu-se na Província de Santa Fé pelo italiano Sebastião Gaboto (BRUM et al., 2005). Contudo, somente em 1870, que essa cultura foi de fato desenvolvida, ao qual foram cultivados 70 mil hectares nas regiões de Santa Fé, Córdoba, Lá Pampa e Entre Rios (SAGPYA, 2003).

É importante destacar que a qualidade do grão Argentino destinado para panificação é superior ao brasileiro, pois o cereal produzido no Brasil tem menos concentração de glúten e por isso apenas 30\% de sua produção é destinada para panificação, o que faz com que, mesmo que o Brasil produzisse acima de seu consumo, ainda precisaria importar (FAVERO, 2017). Além disso, a Argentina conta com um dos solos mais férteis do mundo e clima mais estável a produção de trigo, o que reduz a necessidade de fertilizantes. Segundo o Ministério das Relações Exteriores (MRE, 2014), a Argentina cultiva atualmente cerca de 36 milhões de hectares entre cereais, sementes oleaginosas, cultivos industriais, hortaliças e frutas, entre estes, 30 milhões de hectares, destinam-se a cultivos de produção extensiva, como a soja, o milho e o trigo. 
Apesar disso, a qualidade do cereal argentino ainda é inferior se comparado com os principais países exportadores mundiais, como Austrália, Canadá e Estados Unidos (MAGGIAN, FELIPE, 2009). Desta forma, seu potencial competitivo vem de sua integração ao MERCOSUL, o que reduz os preços de exportação para países como o Brasil, Paraguai e Uruguai. Além disso, o trigo argentino possui maior competitividade devido aos baixos custos da lavoura e a isenção de taxas (MAGGIAN, FELIPE, 2009).

É inegável a qualidade do trigo produzido na Argentina, porém, a contaminação de matérias estranhas ${ }^{2}$ fazia com que o grão de origem argentina possuísse como característica o excesso de impurezas, acarretando uma ligeira perda de qualidade e, consequentemente, a desvalorização no preço do cereal perante os exportadores (MAGGIAN, FELIPE, 2009). Buscando a resolução deste problema e objetivando a otimização de todos os demais processos da cadeia, desde a preparação do solo, escolha dos grãos para semente, passando pelo plantio e colheita, até o armazenamento e distribuição, foi criado o programa nacional de qualidade do trigo, com a resolução $\mathrm{N}^{\circ} 334 / 2003$, através da SAGPYA (SAGPYA, 2003).

Basicamente o programa tem como objetivos: melhorar a apresentação do grão, oferecendo ao mercado o produto de acordo com os requisitos de demanda e qualidade exigidos; identificar as exigências de qualidade dos mercados interno e externo, direcionando o produto com características para cada destino; estabelecer uma política de distribuição e preparação de sementes que permita a diferenciação e agrupamento dos cultivares por tipo e qualidade, e; orientar a classificação da mercadoria conforme as demandas de diferentes mercados, visando garantir o nível máximo de segurança no abastecimento do trigo argentino (SAGPYA, 2003).

Atualmente, o Brasil importa aproximadamente $90 \%$ de todo trigo importado da Argentina, dado o baixo custo argentino de produção e distribuição, devido a fatores como solo fértil, clima favorável, sistema de plantio eficiente e proximidade do porto (FÁVERO, 2017). Assim, além da isenção de $10 \%$ da Tarifa Externa Comum (TEC), a logística entre estes dois países é mais facilitada em comparação a outros países concorrentes, fazendo o produto argentino chegar mais barato em solo nacional (FÁVERO, 2017).

\footnotetext{
${ }^{2}$ Segundo a Resolução da Diretoria Colegiada (RDC), $n^{\circ}$ 14, de 28 de março de 2014, art. $4^{\circ}$, item IV, define-se por matéria estranha "qualquer material não constituinte do produto associado a condições ou práticas inadequadas na produção, manipulação, armazenamento ou distribuição" (MINISTÉRIO DA SAÚDE/AGÊNCIA NACIONAL DE VIGILÂNCIA SANITÁRIA, 2014, p. 2).
} 


\subsection{Oferta e demanda de trigo no Brasil e na Argentina}

O trigo está entre as principais culturas de inverno cultivadas no Brasil. Contudo, sua viabilidade produtiva e econômica depende de boas condições climáticas, principalmente climas mais temperados (JESUS JÚNIOR, SIDONIO, MORAES, 2011). Nesse sentido, o cultivo de trigo no Brasil concentra-se mais na região sul, nos estados do Paraná, Rio Grande do Sul e Santa Catarina. Segundo dados da Conab (2018), no ano de 2018, a produção somente destes três estados correspondeu a $90 \%$ da produção total do país (Gráfico 1).

Gráfico 1 - Produção de trigo no Brasil e nos principais estados produtores em mil toneladas métricas (2014 - 2018).

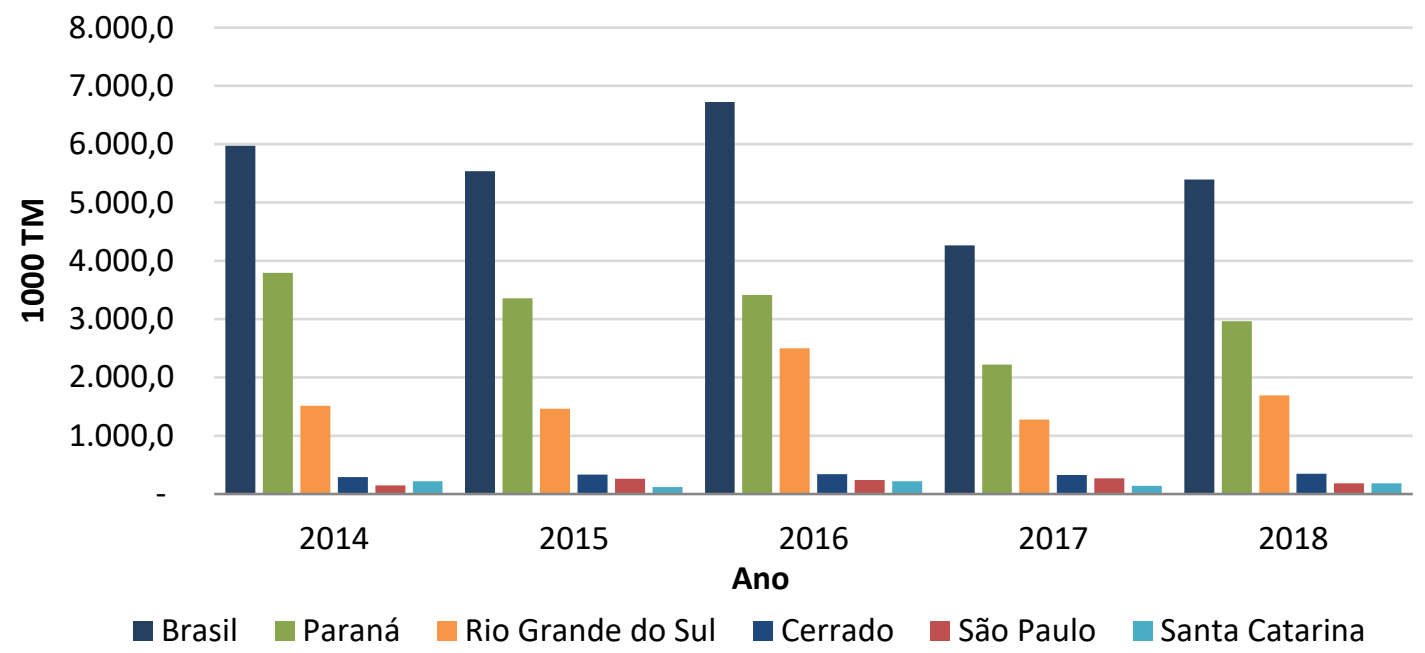

Fonte: CONAB, 2018. Adaptado.

Contudo, existem estudos e cultivares de trigo que estão sendo adaptados ao clima e solo na região do Cerrado brasileiro, ao qual envolvem os estados de Minas Gerais, Goiás, Distrito Federal, Mato Grosso do Sul e Bahia. Segundo a Conab (2018), o cultivo de trigo no cerrado é desenvolvido por meio do plantio irrigado e de sequeiro, sendo o sequeiro com início de plantio na segunda quinzena de janeiro e o irrigado na segunda quinzena de abril (CONAB, 2018). Além disso, o trigo cultivado nessa região possui uma qualidade diferenciada, pela maior concentração de glúten, ao qual produz cultivares do tipo pão e melhorador. $O$ trigo do cerrado também possui maior liquidez no mercado com melhores preços, sobretudo, por colher as primeiras safras (CONAB, 2018).

Entretanto, o Brasil ainda é ineficiente na produção de trigo e sua demanda acaba sendo suprida em grande parte pelas importações, cujo consumo é mais expressivo do que a sua produção (Gráfico 2). Na safra de 2017/2018 o consumo brasileiro de trigo correspondeu a 
$281,43 \%$ a mais do que a produção ofertada, sendo esse número recorde em comparação com as safras anteriores, influenciada, de certo modo, pela queda de $36,64 \%$ da produção e $9,62 \%$ da área colhida nesta safra (2017/2018) com relação à safra anterior (2016/2017).

Gráfico 2 - Oferta e demanda de trigo no Brasil: safras 2014/2015 a 2018/2019

(em mil toneladas métricas)

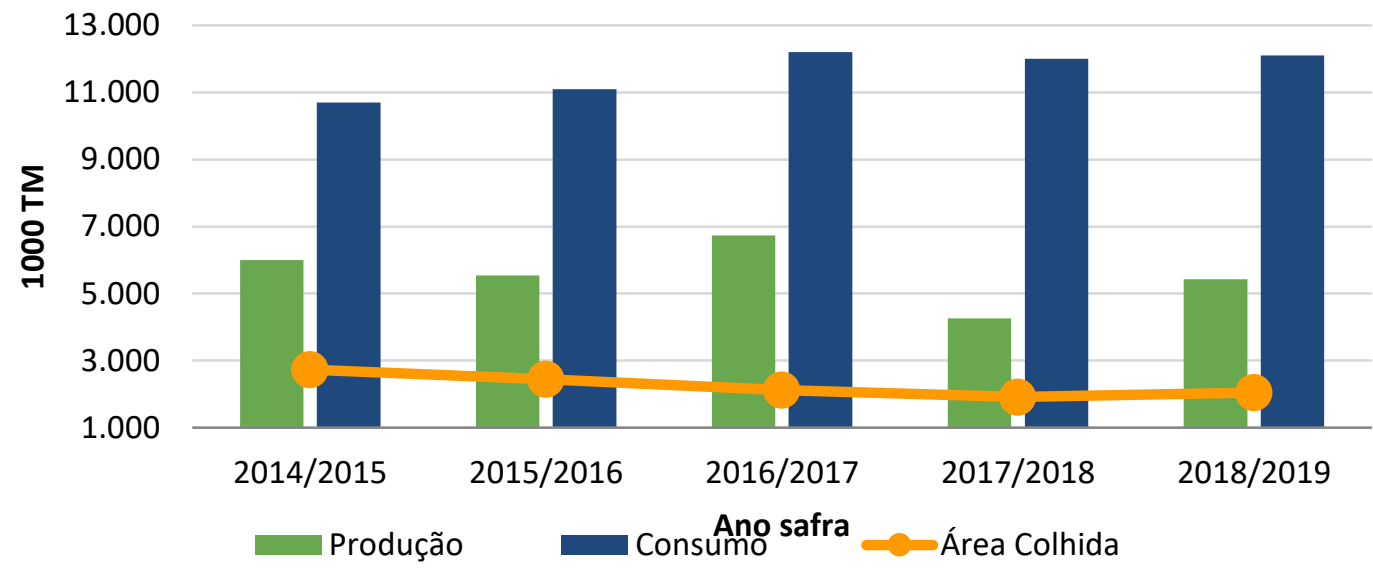

Fonte: USDA, 2018. Adaptado

Nesse viés, o consumo expressivo e a baixa produção de trigo no Brasil, associado à baixa qualidade do cereal, colocaram o país na quarta e terceira posição dos maiores importadores de trigo mundialmente na safra de 2017/2018 e 2018/2019, respectivamente. Na safra 2018/2019 o Brasil importou 7,5 milhões de toneladas de trigo, 7,14\% a mais do que na safra anterior (2017/2018). O maior importador de trigo ainda continua sendo o Egito, o qual importou 12,5 milhões de toneladas na safra de 2018/2019, seguido pela Indonésia, que importou 10 milhões de toneladas nesta mesma safra.

Gráfico 3 - Principais países importadores mundiais de trigo: safras 2014/2015 a 2018/2019 (em mil toneladas métricas)

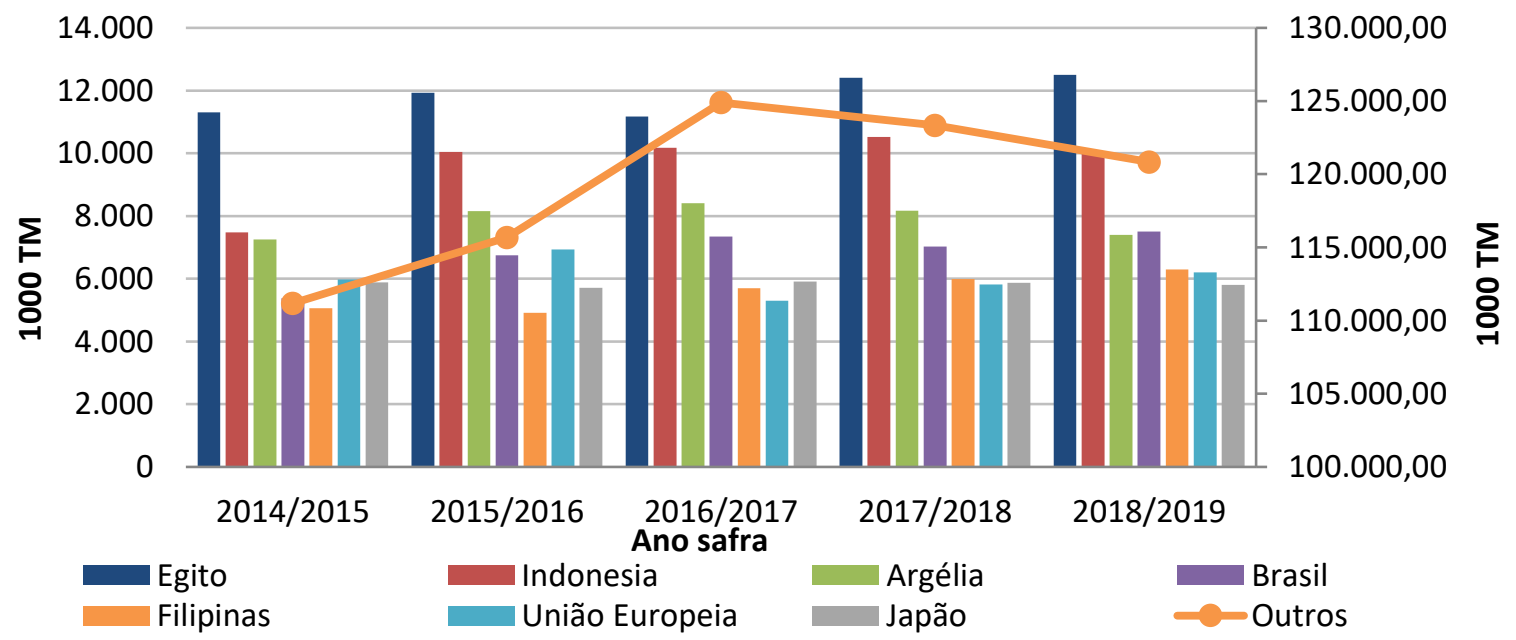

Fonte: USDA, 2018. Adaptado. 
De acordo com os dados da Conab (2018), dentre os principais destinos de consumo interno do trigo no Brasil, na safra de 2017/2018 a maior porcentagem 97,38\% de trigo foi para a moagem industrial na fabricação de farinhas e farelos de trigo, onde somente a produção de farinha de trigo correspondeu à $75 \%$ do total de moagem. Apenas outros $25 \%$ corresponderam à produção de farelo de trigo; e outros $2,61 \%$ restantes foram destinados a sementes.

Além disso, o consumo de farinhas para o mercado vem sendo superior à produção de farinhas produzida internamente no país (tabela 1). No ano de 2017 o consumo total de farinha para o mercado foi de 8.409 mil toneladas, 5,57\%, superior à produção de farinha, que totalizou 7.964 mil toneladas, o que levou o país a importar o total de 445 mil toneladas de farinha. Conforme dados da Abitrigo (2018), o consumo per capita brasileiro de farinha de trigo correspondeu a 42,64 kg, sendo está consumida principalmente em pães, bolachas, massas, biscoitos, dentre outros produtos.

Tabela 1 - Moagem de trigo e consumo de farinha no Brasil do ano de 2013 a 2017 (em mil toneladas)

\begin{tabular}{lccccc}
\hline Produtos & $\mathbf{2 0 1 3}$ & $\mathbf{2 0 1 4}$ & $\mathbf{2 0 1 5}$ & $\mathbf{2 0 1 6}$ & $\mathbf{2 0 1 7}$ \\
\hline Trigo em Grão & 11.276 & 11.194 & 10.425 & 10.733 & 10.619 \\
\hline Farelo de Trigo & 2.819 & 2.799 & 2.606 & 2.683 & 2.655 \\
\hline Farinha Total & 8.457 & 8.396 & 7.819 & 8.050 & 7.964 \\
\hline Farinha/ Mistura Importação & 269 & 335 & 360 & 403 & 445 \\
\hline Total de Farinhas para o Mercado & $\mathbf{8 . 7 2 6}$ & $\mathbf{8 . 7 3 1}$ & $\mathbf{8 . 1 7 9}$ & $\mathbf{8 . 4 5 3}$ & $\mathbf{8 . 4 0 9}$ \\
\hline
\end{tabular}

Fonte: ABITRIGO, 2018. Adaptado.

Já com relação ao trigo argentino (Gráfico 4), a produção do país vem aumentando nos últimos períodos, dada suas condições climáticas favoráveis e melhoramento de técnicas de manejo, como preparação do solo e escolha dos grãos para semente. Segundo dados da USDA (2018), após uma redução da produção de 18,88\% da safra de 2014/2013 para a safra de 2014/2015, causada pelas chuvas intensas nesse período, a produção de trigo argentino vem crescendo gradativamente ao longo das safras.

A safra de 2016/2017 registrou um aumento de 62,83\% com relação à safra anterior afetada pelas chuvas e na safra subsequente (2017/2018) de 0,54\%. Além disso, a produção crescente nessas duas últimas safras também teve contribuição da quantidade de área colhida 
no país, que teve um aumento de $40,95 \%$ na safra de 2016/2017 em comparação a safra de 2015/2016, e em seguida de 4,32\% na safra de 2017/2018 em comparação a de 2016/2017.

Gráfico 4 - Oferta e demanda de trigo na Argentina: safras 2014/2015 a 2018/2019

(em mil toneladas métricas)

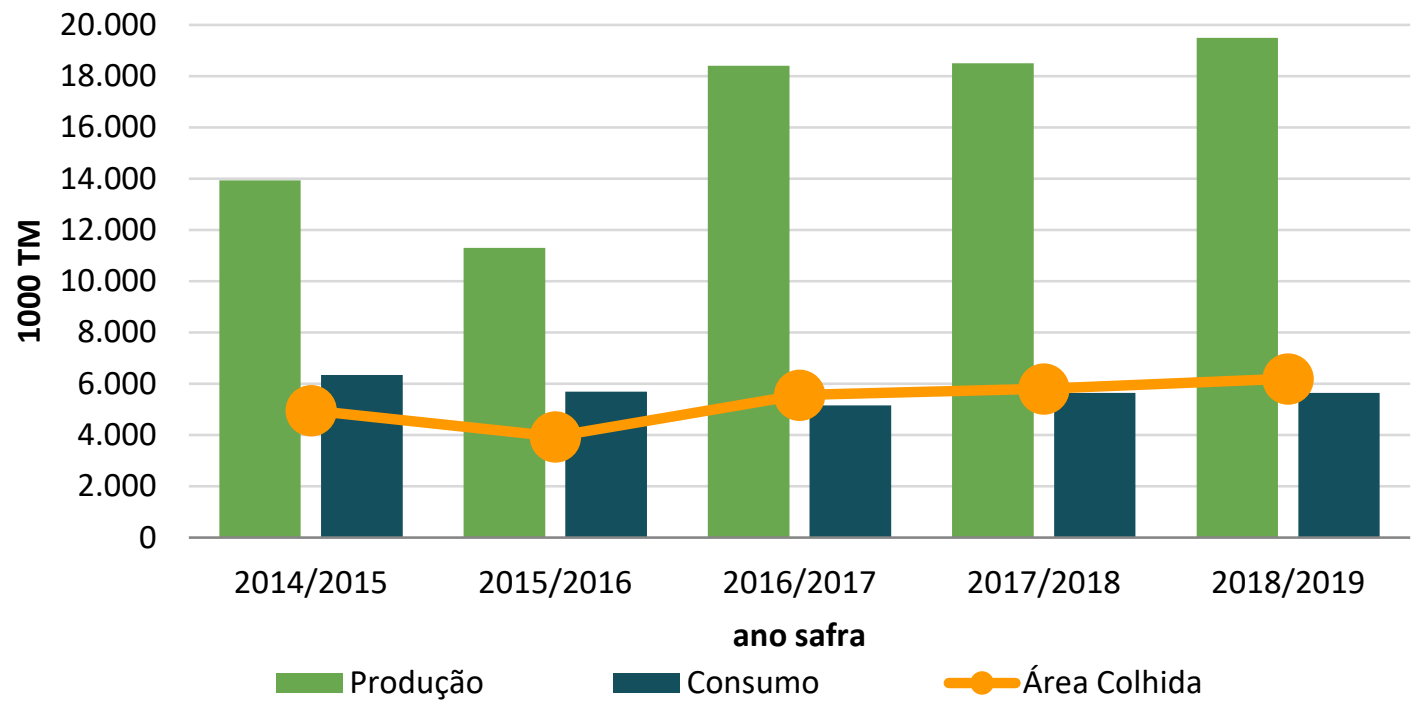

Fonte: USDA, 2018. Adaptado.

Entre os países mais exportadores de trigo mundialmente, a Rússia e a Argentina (mesmo não estando no ranking dos maiores exportadores) têm ganhado destaque nas últimas safras (Gráfico 5). Segundo dados da USDA (2018), a Rússia exportou 41 milhões de toneladas de trigo durante a safra de $2017 / 2018,48,94 \%$ a mais do que a safra de $2016 / 2017$, registrando recorde nas exportações de trigo no país ao longo das safras, superando, inclusive as exportações da União Europeia (UE), líder das exportações de trigo nas safras de 2014/2015 e 2015/2016. O potencial da Rússia nas exportações de trigo é influenciado, de modo geral, por boas condições climáticas a produção de trigo, de logística (principalmente de baixos custos de frete para o norte da África, África e Oriente Médio) e de armazenagem de grãos, bem como, de maior espaço de mercado, dada a queda das exportações da UE, em especial da França e da Itália (USDA, 2018). 
Gráfico 5 - Maiores exportadores de trigo e a Argentina: safras 2014/2015 a 2018/2019

(em percentual do total)

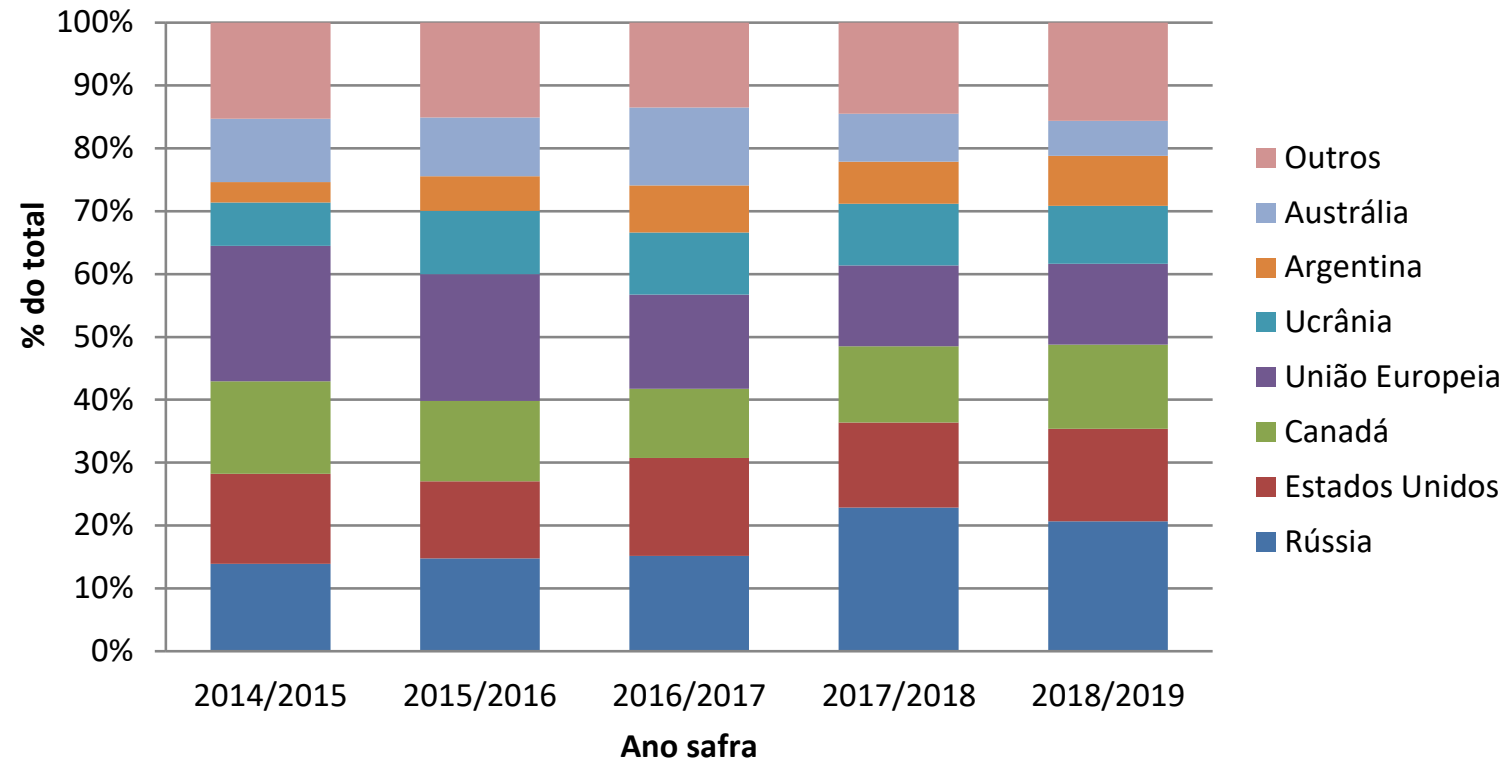

Fonte: USDA, 2018. Adaptado.

Já com relação às exportações de trigo da Argentina, principal país exportador de trigo do MERCOSUL, tem apresentado altas taxas de crescimento e competitividade ao longo das quatro últimas safras, ao qual representou nesta safra de $2017 / 2018,6,62 \%$ das exportações mundiais. Segundo dados da USDA (2018), estima-se que as exportações de trigo da Argentina na safra de 2018/2019 sejam de 14,2 milhões de toneladas, um aumento de $267,87 \%$ em comparação a safra de 2013/2014 e de 18,33\% com relação à safra de 2017/2018.

Sua potencialidade exportadora é influenciada pelo acréscimo de produção e de área plantada deste cereal, assim como a criação de programas e políticas de incentivo ao setor, como destacados pela SAGPYA (2004). Além disso, a Argentina possui um mercado de exportação diversificado composto no ano de 2017 por 88 países, ao qual exportou 64,86\% de toda a sua produção (USDA, 2018).

Entre os principais exportadores de trigo para o Brasil, a Argentina é o país que mais fornece esse cereal (Gráfico 6). As importações de trigo da Argentina representam no ano de 2018, 87,18\% do total de importações do Brasil, ao qual o restante foi importado dos EUA (3,96\%) e do Paraguai $(4,85 \%)$, entre outros países (4,01\%). A participação expressiva da Argentina nas importações brasileiras de trigo é influenciada, em larga medida, pela zona de livre comércio consolidada em 1995. 
Gráfico 6 - Importações brasileiras de trigo por país de 2010 a 2018 (em percentual do total)

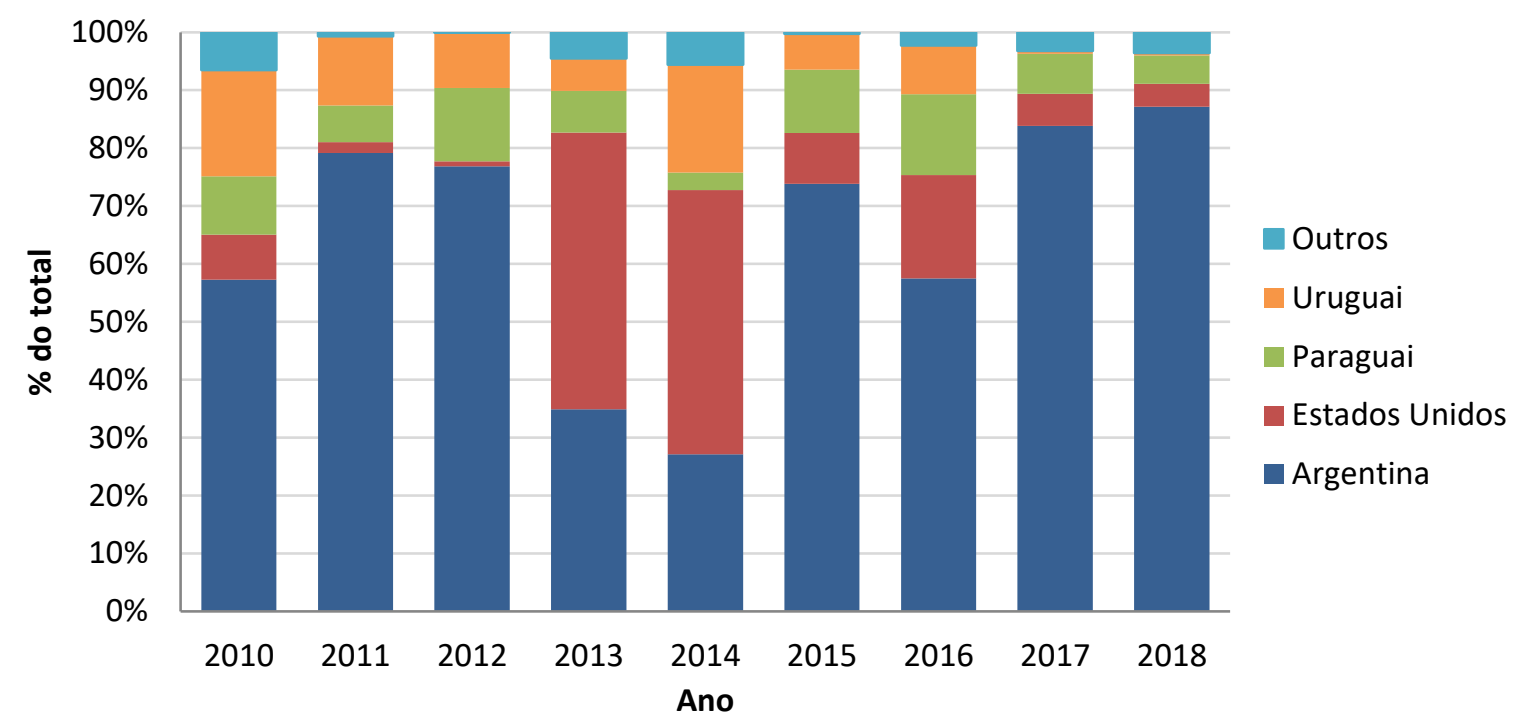

Fonte: ABITRIGO, 2018. Adaptado.

Ademais, importar o trigo argentino se torna mais barato para o Brasil, uma vez que os custos de produção são mais altos internamente, bem como os onerosos fretes e tributações, deixando o produto mais caro. $\mathrm{O}$ trigo argentino é mais barato, principalmente pelo seu menor custo de produção, pois é cultivado pelo plantio convencional, cujos custos são $15 \%$ a $17 \%$ menores do que o sistema de plantio direto (muito utilizado no Brasil), pela não utilização de insumos químicos, como os fertilizantes (BRUM; SILVA; MÜLLER, 2005).

\subsection{Novas iniciativas de incentivo à cultura do trigo}

Buscando novos formatos de organização de produção os produtores rurais buscaram integrar-se entre eles por meio de agroindústrias, geralmente organizadas sob a forma de cooperativas. O embrião desse sistema de produção teve início em 1964 no Estado de Santa Catarina, posteriormente disseminado para outros estados e regiões do país. Essa forma de coordenação da produção em que o produtor se encontra vinculado à agroindústria por meio de contratos, levou a um significativo aumento da produtividade física do setor agrícola familiar (STOFFEL; COLOGNESE, 2005).

Com a modernização agrícola formam-se as bases de implantação dos modernos complexos agroindustriais. Estes complexos estão centrados nas cadeias de produção de determinada matéria-prima básica, que é transformada industrialmente em diferentes produtos finais (BATALHA, 2001). Os produtores rurais inseridos nestes complexos são os 
agentes produtivos responsáveis pela produção de matéria-prima básica - como grãos e carnes (BATALHA, 2001).

No caso das cooperativas ligadas a triticultura, estas "atuavam como unidades de comercialização dos produtos dos associados, de revenda de insumos e de assistência técnica" (ROSSI; NEVES, 2004 apud ACOSTA et al., 2018, p. 9). As primeiras cooperativas tritícolas foram criadas no estado do Rio Grande do Sul, sendo estas "responsáveis pelo processo de transformação da estrutura produtiva e socioeconômica da agricultura", até no processo de como a produção da soja foi desenvolvida (ACOSTA et al., 2018, p. 9).

Entretanto, observa-se uma grande redução de seus associados quanto ao cultivo de trigo. Segundo Acosta et al. (2018), editor técnico da Embrapa trigo de Passo Fundo (RS), já no ano de 2005, a maioria das cooperativas contava somente com 40 a $50 \%$ de seus associados que ainda produziam trigo, em casos particulares, essa estimativa caiu para $10 \%$ de associados que ainda produziam trigo.

Segundo as cooperativas, as principais dificuldades encontradas por seus associados quanto à comercialização de trigo

são forte instabilidade do mercado, com preços geralmente muito baixos; dificuldades de enquadrar o produto ofertado aos padrões exigidos pela indústria, em termos qualitativos; importações constantes sem uma política oficial definida para o produto (BRUM; MULLER, 2008, p. 165).

Neste cenário, novos projetos de incentivo estão surgindo, principalmente no sul do Brasil, onde o papel das cooperativas e seus associados são fundamentais para o desenvolvimento e sucesso dessa cultura. No Quadro 1 está apresentado uma estrutura básica de modelo de trabalho já implantada e praticada por cooperativas do ramo tritícola.

Essa estrutura de trabalho, envolve a organização interna das cooperativas, os produtos oferecidos (cultivares), o rastreamento de produtores e a garantia de serviços e de assistência técnica aos produtores. Para Acosta et al. (2018), as cooperativas que adotam e aplicam esse modelo conseguem assegurar sua viabilidade e precisão quanto aos resultados esperados. Por outro viés, por se tratar de uma cadeia produtiva um pouco esquecida, é imprescindível identificar os principais desafios para a produção de trigo, formas de resolvê-los, e as inovações em processos ou serviços esperados pelo mercado em relação à qualidade do produto (KONZEN; OLIVEIRA, 2015). 
Quadro 1 - Estrutura básica de modelo de trabalho já adotado e aplicado por algumas cooperativas tritícolas

\begin{tabular}{|c|c|}
\hline Estrutura & Descrição \\
\hline Organização Interna & $\begin{array}{l}\text { Possuir uma organização, com corpo técnico treinado (departamento específico) } \\
\text { e em número suficiente para atender às possíveis demandas que venham a surgir, } \\
\text { visando disponibilizar assistência técnica gratuita e constante, desde o plantio até } \\
\text { a colheita. }\end{array}$ \\
\hline Produto & $\begin{array}{l}\text { Disponibilizar cultivares testados e aprovados, visando o atendimento dos } \\
\text { padrões de qualidade exigidos pelo mercado consumidor (ex.: trigo tipo pão, trigo } \\
\text { branqueador etc.). }\end{array}$ \\
\hline Produtores & $\begin{array}{l}\text { Rastrear produtores que estejam dispostos a aderir ao contrato modelo proposto } \\
\text { pela organização, onde se estipula que haverá compra dos grãos por um valor } \\
\text { justo (preço mínimo), com a contrapartida de que serão adquiridas todas as } \\
\text { sementes e insumos junto à cooperativa e entregue a produção, além disso, visa } \\
\text { definir padrões de qualidade, que irão definir ganhos extras nos preços praticados } \\
\text { perante o produtor. Observa-se que este número precisa ser representativo e } \\
\text { viável dentro de uma área de atuação, direcionando a demanda dos cultivares a } \\
\text { serem plantados. }\end{array}$ \\
\hline $\begin{array}{l}\text { Prestações de Serviços } \\
\text { e Assistência Técnica }\end{array}$ & $\begin{array}{l}\text { Garantir assistência técnica e acompanhamento in loco durante o ciclo de } \\
\text { desenvolvimento e manejo, para garantir os melhores resultados possíveis, nos } \\
\text { quesitos de quantidade quanto de qualidade dos grãos. }\end{array}$ \\
\hline
\end{tabular}

Fonte: ACOSTA et al., 2018. Editado.

Neste sentido, as organizações estão buscando estabelecer novos cenários de incentivo, juntamente com os órgãos de pesquisa como a Embrapa e Emater - Rio Grande do Sul (RS). Mesmo as cooperativas sendo de grande porte, estruturadas e apresentando uma saúde financeira estável, elas enfrentam desafios (gargalos técnicos, financeiros e logísticos) para convencer os produtores a investirem em plantio e desenvolvimento da cadeia do trigo, e por consequência, verificar um aumento real em área plantada. Diante disso, se fez necessário cada organização criar o seu próprio modelo de trabalho (KONZEN; OLIVEIRA, 2015).

\section{Considerações finais}

O trigo tem grande importância econômica e social, sendo um dos cereais mais consumidos mundialmente. É considerado como um dos principais insumos básicos, tanto para a alimentação humana como animal. Entretanto, dada sua importância, o Brasil é extremamente dependente de sua importação, sendo que no país a demanda de trigo é superior à sua produção. $O$ déficit de trigo no mercado brasileiro se dá principalmente pelas condições climáticas não serem tão adequadas ao seu cultivo, sendo que o grão é produzido, em maior escala, somente em dois estados brasileiros; no Rio Grande do Sul e no Paraná, os quais apresentam o clima mais propicio para o cultivo. 
Além disso, como podemos ver a partir do contexto histórico, no Brasil foram poucos os incentivos políticos e econômicos ao cultivo do trigo. Os altos custos de produção, os preços baixos pagos aos produtores e os altos custos de logística contribuem para o baixo interesse dos agricultores em cultivar o grão, o que gera um baixo volume de produção desse cereal, fator este que caracteriza o país como um grande dependente do trigo de origem externa.

A Argentina, portanto, é a principal fornecedora de trigo ao Brasil, essencialmente devido a facilidade de importação, proporcionada pela zona de livre comércio e pelas baixas taxas alfandegárias, condicionadas pelo acordo do MERCOSUL. Além disso, o trigo argentino apresenta qualidade superior ao brasileiro, influenciado, sobretudo, pelas condições edafoclimáticas, pelos solos férteis que favorecem a produção deste cereal e a um conjunto de políticas socioeconômicas do governo argentino. O resultado é um produto de maior qualidade e de maior competitividade em detrimento ao produto brasileiro.

O surgimento de novos programas de fomento específicos nas cooperativas brasileiras tem procurado manter e elevar a relevância da cultura do trigo, apresentando um cenário de valorização da produção através de auxílio no cultivo. Estes fatores visam reverter a insuficiência interna encontrada atualmente, na busca em aumentar a produção, a produtividade e o padrão de qualidade exigida pelo mercado consumidor. Quanto às limitações do estudo percebeu-se pouca disponibilidade de informações quanto ao histórico, cultivo, políticas de incentivo e informações mercadológicas mais detalhadas sobre a cadeia tritícola da Argentina.

Além disso, este estudo fica limitado à revisão bibliográfica e a um estudo de caso, abordando somente a relação comercial entre o Brasil e a Argentina, não sendo analisadas de forma direta as influências dos demais países, que também interferem na cadeia produtiva do trigo a nível mundial. Desta forma, como sugestão de trabalhos futuros, poderiam ser aplicados análises estatísticas que de fato quantificam a relação comercial entre estes dois países e os demais que contribuem tanto na produção, importação, exportação, etc. do trigo mundialmente.

\section{Agradecimento}

O presente trabalho foi realizado com apoio da Coordenação de Aperfeiçoamento de Pessoal de Nível Superior - Brasil (CAPES) - Código de Financiamento 001. 


\section{Referências}

ACOSTA, A. da S. et al. Dinâmica e cenário para a produção de trigo em áreas de atuação de cooperativas no Brasil. Passo Fundo: Embrapa Trigo, 2018. 51 p.

ASSOCIAÇÃO BRASILEIRA DA INDÚSTRIA DO TRIGO - ABITRIGO. O Triticultor e o Mercado. São Paulo: 2011. Disponível em:

<http://abitrigo.com.br/associados/arquivos/cartilha_triticultor.pdf>. Acesso em: 07 nov. 2018. ASSOCIAÇÃO BRASILEIRA DA INDÚSTRIA DO TRIGO - ABITRIGO. Estatísticas sobre o mercado do trigo, farinha e derivados. Disponível em: <http://www.abitrigo.com.br/estatisticas.php>. Acesso em: 02 nov. 2018.

BRASIL. Decreto n. 210, de 27 de fevereiro de 1967. Estabelece normas para o abastecimento de trigo, sua industrialização e comercialização e dá outras providências. Diário Oficial da República Federativa do Brasil. Poder Executivo, Brasília, DF, 27 fev. 1967. Disponível em: <https://www.planalto.gov.br/ccivil_03/decreto-lei/1965-1988/Del0210.htm>. Acesso em: 02 nov. 2018.

BRASIL. Lei no 8.096, de 21 de novembro de 1990. Dispõe sobre a Comercialização e Industrialização do Trigo, e dá outras providências. Diário Oficial da República Federativa do Brasil. Poder Executivo, Brasília, DF, 22 nov. 1990. Disponível em:

<http://www2.camara.leg.br/legin/fed/lei/1990/lei-8096-21-novembro-1990-377064publicacaooriginal-1-pl.html>. Acesso em: 07 nov. 2018.

BRASIL. Instrução Normativa no 1, de 27 de janeiro de 1999. Aprova a norma de identidade e qualidade do trigo para comercialização interna. Ministério da Agricultura e do Abastecimento. Diário Oficial da República Federativa do Brasil. Poder Executivo, Brasília, DF, 29 jan. 1999.

Disponível em: <http://sistemasweb.agricultura.gov.br/sislegis/action/detalhaAto.do?method=consultarLegislacaoFederal>. Acesso em: 08 nov. 2018.

BATALHA, M. O. Gestão agroindustrial. 2. ed. São Paulo: Atlas, 2001.

BRUM, A. L. et. al. A competitividade do trigo brasileiro diante da concorrência argentina. UNIJUÍ, 2003.

BRUM, A. L. et al. A competitividade do trigo brasileiro diante da concorrência argentina. $O$ comércio internacional e a competitividade pelo custo de produção. Revista Galega de Economia, vol. 14, núm. 1-2 (2005), p. 1-15. Disponível em: < http://www.usc.es/econo/RGE/Vol14_1_2/Outros/art3b.pdf> Acesso em: 30 de out. de 2018.

BRUM, A. L.; SILVA, C. V. K. da; MÜLLER, P. K. O Trigo Brasileiro Diante da Concorrência Argentina: o Comércio Internacional e a Competitividade. Revista Desenvolvimento em Questão, Editora Unijuí, ano 3, n. 5, jan./jun., 2005, p. 135-150. Disponível em: <http://www.redalyc.org/pdf/752/75230508.pdf>. Acesso em: 03 de nov. de 2018.

BRUM, A.L.; MULLER, P. K. A realidade da cadeia do trigo no Brasil: o elo produtores/cooperativas. Revista de Economia Rural (RER). vol. 46, $n^{\circ} 1$, p. 145-169, jan/mar 2008. Rio de Janeiro.

COMPANHIA NACIONAL DE ABASTECIMENTO (CONAB). Safra Brasileira de Grãos. 2018. Informações Agropecuárias. Disponível em: <https://www.conab.gov.br/infoagro/safras/graos>. Acesso em: 02 de nov. de 2018.

CORTE, V. F. D. et al. O Agronegócio do Trigo e seus Derivados: O Efeito da Desregulamentação e Redução dos Subsídios no Brasil. Revista Brasileira de Gestão e Inovação. v.3. n.1, set/dez. 
2015. Disponível em:

<http://www.ucs.br/etc/revistas/index.php/RBGl/article/view/3668/2286> Acesso em: 15 nov. 2018.

CUNHA, G. R. da (Ed.). Oficina sobre trigo no Brasil: bases para a construção de uma nova triticultura brasileira. Passo Fundo: Embrapa Trigo, 2009. Disponível em:

<https://www.embrapa.br/busca-de-publicacoes/-/publicacao/852640/oficina-sobre-trigo-nobrasil-bases-para-a-construcao-de-uma-nova-triticultura-brasileira>. Acesso em: 02 nov. 2018.

DATHEIN, R. Mercosul: antecedentes, origem e desempenho recente. Revista de Economia, Curitiba, v. 31, n. 1, p. 7-40, janeiro-junho/2005. Disponível em:

<https://revistas.ufpr.br/economia/article/view/5026/379>. Acesso em: 10 nov. 2018

DEPARTAMENTO DE AGRICULTURA DOS ESTADOS UNIDOS - USDA. Relatórios do USDA e acompanhamento do mercado agrícola, 2018. Disponível em:

<https://www.noticiasagricolas.com.br/noticias/usda/>. Acesso: 02 nov. 2018.

FAVERO, D. A. O comércio Brasil - Argentina: análise do mercado internacional e viabilidade da triticultura. Cruz alta, 2017. Dissertação de Mestrado. Programa de Pós-Graduação em Mestrado Profissional em Desenvolvimento Rural, UNICRUZ - 2017. 79 f.

FIGUEIREDO, A., SANTOS, M. Evolução das vantagens comparativas do Brasil no comércio mundial de soja. Revista de Política Agrícola, 14, Jun. 2005. Disponível em: <https://seer.sede.embrapa.br/index.php/RPA/article/view/526>. Acesso em: 12 Nov. 2018.

GARCIA, J. D. O Trigo Brasileiro e a falta de autossuficiência: Uma identificação de problemas. Universidade Federal do Paraná, 2011. Disponível em:

<https://acervodigital.ufpr.br/bitstream/handle/1884/32675/R\%20-\%20E\%20-

\%20JOAO\%20DONIZETI\%20GARCIA.pdf?sequence=1\&isAllowed=y> . Acesso em: 14 nov. 2018.

GERHARDT, T. E.; SILVEIRA, D. T. (Org.). Métodos de pesquisa. 1. ed. Porto Alegre: UFRGS, 2009. $120 \mathrm{p}$.

GONTIJO, C. As duas vias do princípio das vantagens comparativas de David Ricardo e o padrãoouro: um ensaio crítico. Revista de Economia Política, vol. 27, no 3 (107), p. 413-430, julhosetembro/2007. Disponível em: <http://www.rep.org.br/pdf/107-6.pdf> Acesso em: 10 nov. 2018.

GRANATO, L.; BATISTA, I. R. Mercosul à prova: estratégias e limites da integração regional periférica. Revista Brasileira de Políticas Públicas e Internacionais. v.3, n.1, Junho/2018, pp. 230253. Disponível em: <file:///C:/Users/Usu\%C3\%A1rio/Downloads/36178-98148-1-PB.pdf>. Acesso em: 02 nov. 2018.

JESUS JÚNIOR, C. de; SIDONIO, L.; MORAES, V. E. G. de. Panorama das importações de trigo no Brasil. Agroindústria. BNDES, Setorial 34, p. 389-420. 2011. Disponível em:

<https://web.bndes.gov.br/bib/jspui/bitstream/1408/1602/1/A\%20BS\%2034\%20Panorama\%2 Odas\%20importa\%C3\%A7\%C3\%B5es\%20de\%20trigo\%20no\%20Brasil_P.pdf>. Acesso em: 10 de nov. de 2018.

KONZEN; R. R. P.; OLIVEIRA, C. A. Intercooperação entre cooperativas: barreiras e desafios a serem superados. Revista de Gestão e Organizações Cooperativas - RGC. Colégio Politécnico da Universidade Federal de Santa Maria, RS. V.2, n.4, jul./dez., 45-58. 2015.

KRUGMAN, P. R.; OBSTFELD, M. Economia Internacional - Teoria e Política. São Paulo: Makron Books, 1999. 
MAEHLER, A. E. et al. Integração Brasil - Argentina no Mercosul: Uma análise de seus efeitos a partir de um território de fronteira. Revista da Administração e Turismo - ReAT, vol. 8, $n^{\circ} 4, p$. 792-811, janeiro-junho/2016. Disponível em:

<https://www.lume.ufrgs.br/bitstream/handle/10183/170740/001054770.pdf?sequence=1>. Acesso em: 09 nov. 2018.

MAGGIAN, R. C. FELIPE, F. I. Aspectos da competitividade da cadeia tritícola no Brasil e na Argentina. Sociedade Brasileira de Economia, Administração e Sociologia Rural. Porto Alegre, 2009. Disponível em: <https://www.cepea.esalq.usp.br/br/documentos/texto/aspectos-dacompetitividade-da-cadeia-triticola-no-brasil-e-na-argentina-a-artigo-publicado-no-xlviicongresso-da-sober-2009.aspx>. Acesso em: 30 de out. de 2018.

MINISTÉRIO DA SAÚDE/AGÊNCIA NACIONAL DE VIGILÂNCIA SANITÁRIA. Resolução - RDC $\mathbf{N}^{\circ} \mathbf{1 4}$, de 28 de março de 2014. Dispõe sobre matérias estranhas macroscópicas e microscópicas em alimentos e bebidas, seus limites de tolerância e dá outras providências. Disponível em: < http://bionovadesin.com.br/rdc-n-14/>. Acesso em: 17 de fev. de 2019.

MINISTÉRIO DAS RELAÇÕES EXTERIORES - MRE. Argentina: Comércio Exterior. Disponível em: <http://www.investexportbrasil.gov.br/sites/default/files/publicacoes/indicadoresEconomicos/ INDArgentina.pdf>. Acesso: 02 nov. 2018.

MINISTÉRIO DA INDÚSTRIA, COMÉRCIO EXTERIOR E SERVIÇOS (MDIC). Estatísticas do Comércio Exterior. 2018. Disponível em: <http://www.mdic.gov.br/comercio-exterior/estatisticas-decomercio-exterior/comex-vis>. Acesso em: 04 de nov. de 2018.

OLIVEIRA NETO, A. A. de; CANDICE, M. R. S (Orgs). A cultura do trigo. Brasília: Conab, 2017. 218 p.

PEROSA, B. B. Novos mecanismos de coordenação no mercado do trigo brasileiro no período 1990/2005. 2007. 165 f. Dissertação (Mestrado em Engenharia de Produção) - Universidade Federal de São Carlos, São Carlos. 2007. Disponível em:

<https://repositorio.ufscar.br/handle/ufscar/3537?show=full>. Acesso em: 07 nov. 2018.

PEROSA, B. B.; PAULILLO, L. F. Novas formas de coordenação setorial em cadeias agroindustriais após 1990: o caso dos elos tritícola e moageiro brasileiros. Gestão \& Produção, São Carlos, v. 16, n. 1, p. 85-98, jan. - mar. 2009. Disponível em:

<http://www.scielo.br/pdf/gp/v16n1/v16n1a09.pdf>. Acesso em: 07 nov. 2018.

PRODANOV, C. C; FREITAS, E. C. de. Metodologia do trabalho científico: métodos e técnicas da pesquisa e do trabalho acadêmico. 2. ed. Novo Hamburgo: Feevale, 2013.

RAMOS, Albenides. Metodologia da pesquisa científica: como uma monografia pode abrir o horizonte do conhecimento. São Paulo: Atlas, 2009.

SECRETARÍA DE AGRICULTURA, GANADERÍA Y PESCA (SAGPYA). Resolución SAGPYA 334 de 2003 - Creación Programa Nacional De Calidad De Trigo. Dirección de Registro de Variedades. Buenos Aires, 23 de abr. 2003. Disponível em:

$<$ https://www.inase.gov.ar/index.php?option=com_remository\&/temid=102\&func=startdown\& id $=569>$ Acesso em: 15 nov. 2018.

SOARES, R. P. Avaliação Econômica da Política Tritícola de 1967 a 1977. Brasília: Comissão de Financiamento da Produção, 1980. Disponível em: <https://home.unicruz.edu.br/wpcontent/uploads/2018/05/Diego-Alexsander-F\%C3\%A1vero-O-COM\%C3\%89RCIO-BRASIL\%E2\%80\%93-ARGENTINA-AN\%C3\%81LISE-DO-MERCADO-INTERNACIONAL-E-VIABILIDADE-DATRITICULTURA.pdf>. Acesso em: 14 nov. 2018. 
STOFFEL, J. A.; COLOGNESE, S. A. Formas de organização produtiva da pequena produção agrícola familiar no Oeste do Paraná: potencialidades e obstáculos. Cadernos de Economia, Chapecó, v. 9, n. 16, p. 25-42, 2005. 